Article

\title{
Prediction of Postoperative Infection for Patients Undergoing Gastrointestinal Surgery: Findings from Electronic Health Records
}

\author{
Kyoko Nakazawa ${ }^{1, * D}$, Takashi Ishikawa ${ }^{2}$, Akira Toyama ${ }^{3} \mathbb{D}$, Toshifumi Wakai ${ }^{4}$ and \\ Kohei Akazawa ${ }^{5}$ iD
}

1 Department of Medical Informatics and Statistics, Niigata University Graduate School of Medical and Dental Sciences, and Division of Pharmacy, Niigata University Medical and Dental Hospital, Niigata 951-8520, Japan

2 Department of Medical Informatics, Niigata University Medical and Dental Hospital, and Division of Digestive and General Surgery, Niigata University Graduate School of Medical and Dental Sciences, Niigata 951-8520, Japan; takish@med.niigata-u.ac.jp

3 Division of Pharmacy, Niigata University Medical and Dental Hospital, Niigata 951-8520, Japan; toyama@med.niigata-u.ac.jp

4 Division of Digestive and General Surgery, Niigata University Graduate School of Medical and Dental Sciences, Niigata 951-8520, Japan; wakait@med.niigata-u.ac.jp

5 Department of Medical Informatics, Niigata University Medical and Dental Hospital, Niigata 951-8520, Japan; akazawa@med.niigata-u.ac.jp

* Correspondence: nakakyo-nii@umin.ac.jp; Tel.: +81-252272793

Received: 25 October 2020; Accepted: 17 November 2020; Published: 19 November 2020

\begin{abstract}
Introduction: Postoperative infection is a major cause of morbidity and prolonged hospitalization in patients undergoing gastrointestinal surgery. This observational study aimed to investigate the risk factors associated with postoperative infection and to develop a prediction model for postoperative infections that occur after gastrointestinal surgery. Methods: The study population comprised 1637 patients who underwent gastrointestinal surgery at Niigata University Medical and Dental Hospital between June 2013 and May 2017. Observational data from 1883 surgical procedures were used in the statistical analyses (including 198 patients who underwent several operations). Results: The generalized estimating equation (GEE) was used to detect significant risk factors, including older age, history of smoking, body temperature greater than $38^{\circ} \mathrm{C}$, non-endoscopic surgical procedures, surgery in the thoracic or lower gastrointestinal tract, and use of medical nutritional products during surgery. The sensitivity and specificity of the GEE model were $88.2 \%$ and $55.1 \%$, respectively. Conclusion: This study established a predictable GEE model, incorporating the data of patients who were hospitalized several times into a prediction analysis, even though the sensitivity was not sufficiently high. The GEE model, which is considered clinically useful, can be constructed using a variety of variables, including those obtained from electronic health records.
\end{abstract}

Keywords: gastrointestinal surgery; postoperative infection; generalized estimating equation; surgical site infection

\section{Introduction}

Postoperative infections (POIs), including surgical site infections (SSIs), in patients who undergo gastrointestinal (GI) surgery could lead to morbidity and prolonged hospitalization, which consequently increases medical costs and ultimately increases the risk of mortality [1]. Ohno et al. reported that following the occurrence of SSIs after GI surgery, the median time for hospitalization was prolonged 
to 9 days, and the median medical cost increased to 576,000 Japanese Yen [2]. POIs comprise SSIs and remote infections. After surgery, remote infections can be observed at various sites, such as the respiratory and urinary tracts; drainage infection, antibiotic-associated diarrhea, and catheter-related bloodstream infections are also observed.

An observational study in Japan reported a POI incidence of $10.7 \%$ in 6582 patients who underwent GI surgery ( $6.8 \%$ for endoscopic surgery and $18.7 \%$ for open surgery) in 2015. In addition, the incidence rates of SSI in the biliary tract, pancreas, and esophagus were approximately $32.4 \%, 31.2 \%$, and $20.1 \%$, respectively, which were remarkably higher than those in other surgical sites [1].

Antibiotics have been widely administered during the perioperative period for the prevention of POIs induced by GI surgery. For example, the guidelines for the prevention of surgical infection recommend that cefazolin sodium should be administered every $3 \mathrm{~h}$ during esophageal cancer resection surgery [3]. Moreover, for patients undergoing biliary and pancreatic surgery, cefmetazole sodium should be administered every $3 \mathrm{~h}$ during surgery [4].

Other studies have identified some risk factors for POIs, including diabetes, obesity, older age, emergency operations, evident contamination (with debris, pus, stool, or other substances) of the injury or the surgical area, open surgery, lower GI ostomy surgery, and lower GI resection surgery $[5,6]$.

In addition to SSIs, there are other infection routes, such as the respiratory and urinary tracts; catheter-related bloodstream infections and other bloodstream infections are major causes of severe sepsis and septic shock. Severe sepsis and septic shock have mortality rates of approximately $50 \%$. Severe sepsis and septic shock are as common and lethal as other acute life-threatening conditions that emergency physicians routinely encounter, such as acute myocardial infarction, stroke, and trauma $[1,7,8]$.

This study aimed to determine the significant factors affecting the incidence of POIs in patients undergoing GI surgery using the generalized estimating equation (GEE) analysis, which includes the clinical data of patients admitted to the hospital that were obtained from the electronic health records. The accuracy of the constructed GEE model was evaluated by cross-validation using internal data and predictive values using external data.

\section{Materials and Methods}

\subsection{Patients}

In this retrospective study, we enrolled 1789 adult patients who underwent GI surgery between June 2013 and May 2017 within the Division of Digestive and General Surgery, Niigata University Medical and Dental Hospital, Japan. In all patients, a total of 2194 operations were performed, which indicated that some patients were hospitalized and underwent GI surgery more than once. This study included only those patients who underwent a single operation during hospitalization. Hence, it excluded 91 patients who underwent several operations during initial hospitalization and 70 surgical procedures performed in patients who tested positive for infections in any bacterial culture tests conducted before the operation. As a result, 1637 patients who underwent a total of 1883 surgical procedures were included in this study. Among these patients, 198 underwent two surgical procedures, 37 underwent three surgical procedures, and 11 underwent more than three surgical procedures (Figure 1).

An individual was considered positive for POIs when incisional infections, SSIs, and remote infections, including respiratory tract, urinary tract, and catheter-related bloodstream infections, were observed. Bacterial infection was confirmed by bacterial isolation. Bacterial colonization was defined as the presence of low-volume bacteria [1]. Data were collected to determine the infection and colonization status of the following antimicrobial-resistant bacteria: Clostridioides difficile, methicillin-resistant Staphylococcus aureus, and extended-spectrum beta-lactamase-producing Enterobacteriaceae [9-11]. The observational period lasted until 5 days after surgery. 
This study protocol was approved by the Institutional Ethics Committee of Niigata University Medical and Dental Hospital (2017-0070).

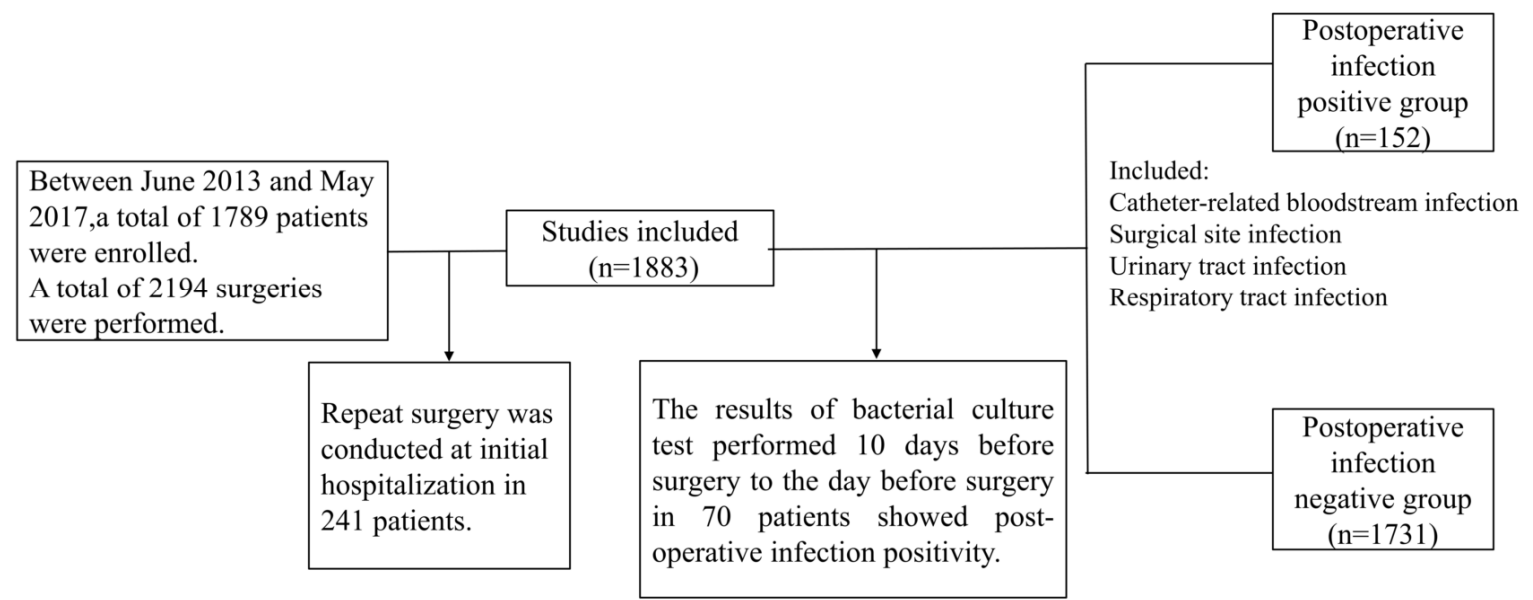

Figure 1. Consort diagram.

\subsection{Variables}

Data on patient characteristics, clinical examinations, surgical procedures, and medications used in the statistical analysis were extracted from the electronic health records of Niigata University Medical and Dental Hospital. All variables and categories are shown in the left column of Tables 1-4.

Table 1. Demographic and patient characteristics.

\begin{tabular}{|c|c|c|c|c|}
\hline \multirow{2}{*}{ Variables } & \multirow{2}{*}{ Total (\%) } & \multicolumn{2}{|c|}{ Postoperative Infection } & \multirow{2}{*}{$\begin{array}{c}\text { Chi-Square Test } \\
p \text {-Value }\end{array}$} \\
\hline & & Positive $(n=135)$ & Negative $(n=1502)$ & \\
\hline Sex & & & & 0.014 \\
\hline Female & $673(41.1)$ & $42(6.2)$ & $631(93.8)$ & \\
\hline Male & $964(58.9)$ & $93(9.6)$ & $871(90.4)$ & \\
\hline $\begin{array}{c}\text { Age at } \\
\text { hospitalization }\end{array}$ & & & & 0.002 \\
\hline 60 years & $476(29.0)$ & $23(4.8)$ & $453(95.2)$ & \\
\hline $61-70$ years & $518(31.6)$ & $40(7.7)$ & $478(92.3)$ & \\
\hline $71-80$ years & $467(28.5)$ & $50(10.7)$ & 417 (89.3) & \\
\hline$\geq 81$ years & $176(10.8)$ & $22(12.5)$ & $154(87.5)$ & \\
\hline History of smoking & & & & 0.003 \\
\hline No & $776(48.1)$ & $46(5.9)$ & $730(94.1)$ & \\
\hline Yes & $836(51.9)$ & $83(9.9)$ & $753(90.1)$ & \\
\hline Missing & 26 & $5(24.0)$ & $21(76.0)$ & \\
\hline Alcohol habit & & & & 0.924 \\
\hline Absence & $1050(65.2)$ & $84(8.0)$ & $966(92.0)$ & \\
\hline Presence & $561(34.8)$ & $46(8.2)$ & $515(91.8)$ & \\
\hline Missing & 26 & $6(24.0)$ & $19(76.0)$ & \\
\hline $\begin{array}{l}\text { Body mass index at } \\
\text { hospitalization }\end{array}$ & & & & 0.671 \\
\hline$<18.5 \mathrm{~kg} / \mathrm{m}^{2}$ & $202(12.3)$ & $19(9.4)$ & $183(90.6)$ & \\
\hline $18.5-24.9 \mathrm{~kg} / \mathrm{m}^{2}$ & $1089(66.5)$ & $91(8.4)$ & $998(91.6)$ & \\
\hline$\geq 25 \mathrm{~kg} / \mathrm{m}^{2}$ & $346(21.1)$ & $25(7.2)$ & $321(92.8)$ & \\
\hline Drainage & & & & $<0.001$ \\
\hline Absence & $439(26.8)$ & $16(3.6)$ & $423(96.4)$ & \\
\hline Presence & $1198(73.2)$ & $119(9.9)$ & 1079 (90.1) & \\
\hline
\end{tabular}


Table 2. Clinical laboratory tests conducted on preoperative days 1-7.

\begin{tabular}{|c|c|c|c|c|}
\hline \multirow{2}{*}{ Variables } & \multirow{2}{*}{ Total (\%) } & \multicolumn{2}{|c|}{ Postoperative Infection } & \multirow{2}{*}{$\begin{array}{l}\text { Chi-Square } \\
\text { Test } p \text {-Value }\end{array}$} \\
\hline & & Positive $(n=135)$ & Negative $(n=1502)$ & \\
\hline Temperature & & & & 0.001 \\
\hline Normal $\left(<38.0^{\circ} \mathrm{C}\right)$ & 1598 (97.6) & $125(7.8)$ & $1473(92.2)$ & \\
\hline Abnormal $\left(\geq 38.0^{\circ} \mathrm{C}\right)$ & $39(2.4)$ & $10(25.6)$ & $29(74.4)$ & \\
\hline White blood cell & & & & 0.019 \\
\hline $\operatorname{Normal}(<10,000 /$ per $\mu \mathrm{L})$ & $1440(88.0)$ & $110(7.6)$ & $1330(92.4)$ & \\
\hline Abnormal $(\geq 10,000$ per $\mu \mathrm{L})$ & $197(12.0)$ & $25(12.7)$ & $172(87.3)$ & \\
\hline Albumin & & & & 0.005 \\
\hline Normal $(\geq 3.0 \mathrm{~g} / \mathrm{dL})$ & $1521(92.9)$ & $117(7.7)$ & $1404(92.3)$ & \\
\hline Abnormal $(<3.0 \mathrm{~g} / \mathrm{dL})$ & $116(7.1)$ & $18(15.5) 1$ & $98(84.5)$ & \\
\hline Hemoglobin & & & & 0.100 \\
\hline Normal ( $\geq 10.0 \mathrm{~g} / \mathrm{dL})$ & $972(59.4)$ & $71(7.3)$ & $901(92.7)$ & \\
\hline Abnormal $(<10.0 \mathrm{~g} / \mathrm{dL})$ & $665(40.6)$ & $64(9.6)$ & $601(90.4)$ & \\
\hline Red blood cell & & & & 0.061 \\
\hline Normal $\left(\geq 10.0 \times 10^{4} / \mu \mathrm{L}\right)$ & $1048(64.0)$ & $76(7.3)$ & $972(92.7)$ & \\
\hline Abnormal $\left(<10.010^{4} / \mu \mathrm{L}\right)$ & $589(36.0)$ & $59(10.0)$ & $530(90.0)$ & \\
\hline International normalized ratio & & & & 0.008 \\
\hline Normal $(<1.15)$ & 1451 (88.6) & $110(7.6)$ & $1341(92.4)$ & \\
\hline Abnormal ( $\geq 1.15)$ & $186(11.4)$ & $25(13.4)$ & $161(86.6)$ & \\
\hline Platelet count & & & & 0.738 \\
\hline Normal $(>75,000 / \mu \mathrm{L})$ & 1509 (92.2) & $123(8.2)$ & $1386(91.8)$ & \\
\hline Abnormal $(<75,000 / \mu \mathrm{L})$ & $128(7.8)$ & $12(9.4)$ & $116(90.6)$ & \\
\hline Gamma-glutamyl transpeptidase & & & & 0.548 \\
\hline Normal $(<47 / \mathrm{L})$ & $1181(72.1)$ & $94(8.0)$ & $1087(92.0)$ & \\
\hline Abnormal $(\geq 47 / \mathrm{L})$ & $456(27.9)$ & $41(9.0)$ & $415(91.0)$ & \\
\hline Alanine aminotransferase & & & & 0.237 \\
\hline Normal $(<47 / \mathrm{L})$ & $1415(86.4)$ & $112(7.9)$ & $1303(92.1)$ & \\
\hline Abnormal ( $\geq 47 / \mathrm{L})$ & $222(13.6)$ & $23(10.4)$ & $199(89.6)$ & \\
\hline Aspartate aminotransferase & & & & 0.129 \\
\hline Normal (Male $<42$, Female $<23 /$ L) & $1395(85.2)$ & $109(7.8)$ & $1286(92.2)$ & \\
\hline Abnormal (Male $\geq 42$, Female $\geq 23 / \mathrm{L}$ ) & $242(14.8)$ & $26(10.7)$ & $216(89.3)$ & \\
\hline Potassium & & & & 0.344 \\
\hline Normal $(3.0-5.5 \mathrm{mmol} / \mathrm{L})$ & $1429(87.3)$ & $114(8.0)$ & $1315(92.0)$ & \\
\hline Abnormal $(<3.0, \geq 5.5 \mathrm{mmol} / \mathrm{L})$ & $208(12.7)$ & $21(10.1)$ & $187(89.9)$ & \\
\hline Sodium & & & & 0.008 \\
\hline Normal (130-150 mmol/L) & $1371(83.8)$ & $102(7.4)$ & $1269(92.6)$ & \\
\hline Abnormal $(<130, \geq 150 \mathrm{mmol} / \mathrm{L})$ & $266(16.2)$ & $33(12.4)$ & $233(87.6)$ & \\
\hline Creatinine & & & & 0.162 \\
\hline Normal $^{1}$ & $1445(88.3)$ & $114(7.9)$ & $1331(92.1)$ & \\
\hline Abnormal $^{2}$ & $192(11.7)$ & $21(10.9)$ & $171(89.1)$ & \\
\hline
\end{tabular}

${ }^{1}$ Male $<1.07$, Female $<0.79 \mathrm{mg} / \mathrm{dL}^{2}$ Male $\geq 1.07$, Female $\geq 0.79 \mathrm{mg} / \mathrm{dL}$.

Table 3. Surgery-related variables and risk of postoperative infection in patients.

\begin{tabular}{ccccc}
\hline \multirow{2}{*}{ Variables } & Total (\%) & \multicolumn{2}{c}{ Postoperative Infection } & \multirow{2}{*}{$\begin{array}{c}\text { Chi-Square Test } \\
p \text {-Value }\end{array}$} \\
\cline { 3 - 3 } & & Positive $(\boldsymbol{n}=\mathbf{1 3 5})$ & Negative $(\boldsymbol{n}=\mathbf{1 5 0 2})$ & $<0.001$ \\
Operation time (hour) & & & & \\
$<3$ & $674(41.2)$ & $37(5.5)$ & $637(94.5)$ & \\
$3-6$ & $614(37.5)$ & $52(8.5)$ & $562(91.5)$ & \\
$6-9$ & $249(15.2)$ & $29(11.6)$ & $220(88.4)$ & \\
$\geq 9$ & $100(6.10)$ & $17(17.0)$ & $83(83.0)$ & \\
Type of surgery & & & $434(96.9)$ & \\
Endoscopic & $448(27.4)$ & $14(3.1)$ & $1068(89.8)$ & \\
Non-endoscopic & $1189(72.6)$ & $121(10.2)$ & & \\
Site of surgery & & & & \\
Thoracic & & & $1455(92.6)$ & \\
Absence & $1572(96.0)$ & $117(7.4)$ & $47(72.3)$ & \\
Presence & $65(4.0)$ & $18(27.7)$ &
\end{tabular}


Table 3. Cont.

\begin{tabular}{|c|c|c|c|c|}
\hline \multirow{2}{*}{ Variables } & \multirow{2}{*}{ Total (\%) } & \multicolumn{2}{|c|}{ Postoperative Infection } & \multirow{2}{*}{$\begin{array}{c}\text { Chi-Square Test } \\
p \text {-Value }\end{array}$} \\
\hline & & Positive $(n=135)$ & Negative $(n=1502)$ & \\
\hline Body surface & & & & 0.434 \\
\hline Absence & $1550(94.7)$ & $130(8.4)$ & 1420 (91.6) & \\
\hline Presence & $87(5.3)$ & $5(5.7)$ & $82(94.3)$ & \\
\hline Peritonitis, abdominal wall & & & & 0.004 \\
\hline Absence & $1222(74.6)$ & $115(9.4)$ & 1107 (90.6) & \\
\hline Presence & $415(25.4)$ & $20(4.8)$ & $395(95.2)$ & \\
\hline $\begin{array}{l}\text { Liver, pancreas, biliary tract, } \\
\text { spleen }\end{array}$ & & & & 0.616 \\
\hline Absence & $1183(72.3)$ & $95(8.0)$ & $1088(92.0)$ & \\
\hline Presence & $454(27.7)$ & $40(8.8)$ & $414(91.2)$ & \\
\hline Lower gastrointestinal tract & & & & 0.172 \\
\hline Absence & $954(58.3)$ & $71(7.4)$ & $883(92.6)$ & \\
\hline Presence & $683(41.7)$ & $64(9.4)$ & $619(90.6)$ & \\
\hline $\begin{array}{l}\text { Others (urinary tract, } \\
\text { generative organ) }\end{array}$ & & & & 0.816 \\
\hline Absence & $1581(96.6)$ & $131(8.3)$ & $1450(91.7)$ & \\
\hline Presence & $56(3.4)$ & $4(7.1)$ & $52(92.9)$ & \\
\hline
\end{tabular}

Table 4. Medication use during surgery and risk of postoperative infection in patients.

\begin{tabular}{|c|c|c|c|c|}
\hline \multirow{2}{*}{ Variables } & \multirow{2}{*}{ Total (\%) } & \multicolumn{2}{|c|}{ Postoperative Infection } & \multirow{2}{*}{$\begin{array}{c}\text { Chi-Square Test } \\
p \text {-Value }\end{array}$} \\
\hline & & Positive $(n=135)$ & Negative $(n=1502)$ & \\
\hline Cardiovascular agents & & & & $<0.001$ \\
\hline Absence & $405(24.7)$ & $11(2.7)$ & $394(97.3)$ & \\
\hline Presence & $1232(75.3)$ & $124(10.1)$ & $1108(89.9)$ & \\
\hline Immunosuppressive agents & & & & $<0.001$ \\
\hline Absence & $168(10.3)$ & $6(3.6)$ & $162(96.4)$ & \\
\hline $1-3$ drugs & $922(56.3)$ & $45(4.9)$ & $877(95.1)$ & \\
\hline$\geq 4$ drugs & $547(33.4)$ & $84(15.4)$ & $463(84.6)$ & \\
\hline Lifestyle disease agents & & & & 0.006 \\
\hline Absence & $1627(99.2)$ & $131(8.1)$ & $1416(91.9)$ & \\
\hline Presence & $10(0.6)$ & $4(40.0)$ & $6(60.0)$ & \\
\hline $\begin{array}{l}\text { Hematopoietic stem cell } \\
\text { mobilizer }\end{array}$ & & & & 0.109 \\
\hline Absence & $1104(67.4)$ & $85(7.7)$ & 1019 (92.3) & \\
\hline $1-3$ drugs & $348(21.3)$ & $38(10.9)$ & $310(89.1)$ & \\
\hline$\geq 4$ drugs & $185(11.3)$ & $12(6.5)$ & $173(93.5)$ & \\
\hline Antibiotics & & & & 0.481 \\
\hline Absence & $138(8.4)$ & $15(10.9)$ & $123(89.1)$ & \\
\hline 1-3 drugs & $1297(79.2)$ & $105(8.1)$ & $1192(91.9)$ & \\
\hline$\geq 4$ drugs & $202(12.3)$ & $15(7.4)$ & $187(92.6)$ & \\
\hline Medical nutritional products & & & & 0.662 \\
\hline Absence & $945(57.7)$ & $83(8.8)$ & $862(91.2)$ & \\
\hline $1-3$ drugs & $435(26.6)$ & $33(7.6)$ & $402(92.4)$ & \\
\hline$\geq 4$ drugs & $257(15.7)$ & $19(7.4)$ & $238(92.6)$ & \\
\hline Gastrointestinal agents & & & & 0.736 \\
\hline Absence & $520(31.8)$ & $42(8.1)$ & 478 (91.9) & \\
\hline 1-3 drugs & $583(35.6)$ & $45(7.7)$ & $538(92.3)$ & \\
\hline$\geq 4$ drugs & $534(32.6)$ & $48(9.0)$ & $486(91.0)$ & \\
\hline Analgesics & & & & 0.516 \\
\hline Absence & $338(20.6)$ & $33(9.8)$ & $305(90.2)$ & \\
\hline 1-3 drugs & $701(42.8)$ & $54(7.7)$ & $647(92.3)$ & \\
\hline$\geq 4$ drugs & $598(36.5)$ & $48(8.0)$ & $550(92.0)$ & \\
\hline Antipsychotics & & & & 1.00 \\
\hline Absence & 1495 (91.3) & $123(8.2)$ & $1372(91.8)$ & \\
\hline Presence & $142(8.7)$ & $12(8.5)$ & $130(91.5)$ & \\
\hline Respiratory agents & & & & 0.907 \\
\hline Absence & $290(17.7)$ & $23(7.9)$ & $267(92.1)$ & \\
\hline Presence & $1347(82.3)$ & $112(8.3)$ & 1235 (91.7) & \\
\hline
\end{tabular}


A history of smoking was considered existent in patients who were smoking upon admission or who used to smoke. Data on age, body weight, and height were collected at the time of hospitalization. Body mass index was categorized according to the National Institutes of Health criteria [12]. Preoperative clinical examination data were gathered only 7 days prior to the patient's surgery. Continuous clinical assessment data were categorized into two groups, normal and abnormal, which were defined based on the Common Terminology Criteria for Adverse Events and the Japanese Committee for Clinical Laboratory Standards classification $[13,14]$. The missing values were assumed to be normal. Endoscopic surgery included laparoscopic and thoracoscopic surgeries. Operation time was divided into the following four groups based on the timing of antibiotic administration: $<3,3-6$, $6-9$, and $\geq 9 \mathrm{~h}$ [15]. Data on the medications administered to patients during surgery were collected and divided into 10 categories based on the drug classes established by the Ministry of Health, Labor and Welfare [16].

\subsection{Statistical Analyses}

Descriptive statistics were expressed as frequency and proportion for categorical variables and median and minimum and maximum values for continuous variables, as appropriate. The chi-square and Fisher's exact tests were performed to determine the proportions of POIs among the categories in a variable.

The missing height values, necessary for calculating body mass index, were estimated following the multiple imputation method using the variables of age, body weight, and height collected at hospital admission, along with history of smoking and alcohol consumption [17].

Some patients were readmitted to the hospital multiple times; therefore, the GEE model was used to identify the risk factors affecting the occurrence of POIs, after adjusting for the effect of confounding factors among variables and intercorrelation of readmissions to the hospital. The explanatory variables in the analysis are shown in Tables $1-4$, and they were obtained during the preoperative and intraoperative periods. The objective variable, comprising the positive and negative POIs, was assumed to follow a binomial distribution. The link function regarding the association between objective and explanatory variables was assumed to be a logit function. The final odds ratios (ORs) and 95\% confidence intervals (CIs) are shown in Table 5 . The Wald test was performed to test the following null hypothesis: "An explanatory variable does not affect the occurrence of POIs, after adjusting for the effects of the other variables." The goodness of fit of the GEE model was evaluated using the quasi-likelihood information criterion (QIC) [18].

Table 5. Results of the generalized estimating equation analyzing the risk factor of postoperative infection.

\begin{tabular}{cccc}
\hline Variables & Odds Ratio & $\mathbf{9 5 \%} \mathbf{C I}$ & $p$-Value \\
\hline Age at hospitalization & Ref & & \\
60 years & 1.52 & $0.89-2.61$ & 0.133 \\
61-70 years & 2.10 & $1.22-3.56$ & 0.007 \\
$71-80$ years & 2.69 & $1.40-5.10$ & 0.003 \\
$\geq 81$ years & & & \\
History of smoking & Ref & $1.41-3.10$ & $<0.001$ \\
No & 2.09 & & \\
Yes & & & 0.002 \\
Drainage & Ref & $1.38-4.22$ & \\
Absence & 2.41 & & \\
Presence & &
\end{tabular}


Table 5. Cont.

\begin{tabular}{|c|c|c|c|}
\hline Variables & Odds Ratio & $95 \%$ CI & $p$-Value \\
\hline \multicolumn{4}{|l|}{ Temperature } \\
\hline Normal $\left(<38.0^{\circ} \mathrm{C}\right)$ & Ref & & \\
\hline Abnormal $\left(\geq 38.0^{\circ} \mathrm{C}\right)$ & 2.83 & $1.27-6.23$ & 0.011 \\
\hline \multicolumn{4}{|l|}{ White blood cell } \\
\hline Normal $(<10,000 / \mu \mathrm{L})$ & Ref & & \\
\hline Abnormal $(\geq 10,000 / \mu \mathrm{L})$ & 2.01 & $1.23-3.29$ & 0.005 \\
\hline \multicolumn{4}{|l|}{ Hemoglobin } \\
\hline Normal ( $\geq 10.0$ g/dL) & Ref & & \\
\hline Abnormal $(<10.0 \mathrm{~g} / \mathrm{dL})$ & 0.71 & $0.48-1.06$ & 0.092 \\
\hline \multicolumn{4}{|l|}{ Type of surgery } \\
\hline Endoscopic & Ref & & \\
\hline Non-endoscopic & 2.75 & $1.53-4.85$ & 0.001 \\
\hline \multicolumn{4}{|l|}{ Surgical site } \\
\hline \multicolumn{4}{|l|}{ Thoracic } \\
\hline Absence & Ref & & \\
\hline Presence & 5.37 & $2.77-10.38$ & $<0.001$ \\
\hline \multicolumn{4}{|l|}{ Lower gastrointestinal tract } \\
\hline Absence & Ref & & \\
\hline Presence & 1.63 & $1.12-2.41$ & 0.011 \\
\hline \multicolumn{4}{|l|}{ Medical nutritional products } \\
\hline Absence & Ref & & \\
\hline $1-3$ drugs & 2.18 & $1.40-3.39$ & 0.001 \\
\hline$\geq 4$ drugs & 4.06 & $2.55-6.42$ & $<0.001$ \\
\hline
\end{tabular}

To evaluate the accuracy of the constructed model, the sensitivity and specificity values were obtained. Furthermore, the external validation of the constructed GEE model was evaluated by measuring the sensitivity and specificity that were estimated using the data of new patients undergoing GI surgery in the same medical hospital between June 2017 and May 2019.

All $p$-values were two-sided, and $p$-values $<0.05$ were considered significant. Statistical analysis was performed using the International Business Machines Statistical Package for the Social Sciences (IBM SPSS) version 21 (IBM ${ }^{\circledR}$ SPSS $^{\circledR}$ Statistics Inc., 2012, or IBM, Chicago, IL, USA) and Stata 8 software for GEE analysis (Stata Corp, College Station, TX, USA).

\section{Results}

\subsection{Patient Characteristics and Incidence of Postoperative Infections}

A consort diagram presenting the process of patient selection is shown in Figure 1. Finally, data on 1883 operations, comprising 152 POI-positive and 1731 POI-negative operations, were used in the analyses. The total proportion of POI-positive patients was $8.2 \%$.

The descriptive statistics of patients who underwent GI surgery at the initial operation are shown in Tables 1-4. As shown in Table 1, the proportion of men was $58.9 \%$, and the median and range of age at hospitalization were 67 years and 15-98 years, respectively. In this study, the proportion of men was slightly higher than that of women, and the incidence of POIs was significantly higher in men than in women. The incidence of POIs in terms of age at hospitalization increased with increasing age. The proportion of POI-positive smokers was higher than that of non-smokers. Patients who underwent surgical drainage had a significantly higher incidence of POI $(9.9 \%)$ than that of those who did not undergo drainage. As shown in Table 2, the proportion of POI-positive patients with body temperature $>38^{\circ} \mathrm{C}$ was higher than that of those with body temperature $<38^{\circ} \mathrm{C}$. In addition, the incidence of POIs in terms of operation time increased as the operation time increased. The most frequent procedures performed at initial surgery were lower GI tract surgery $(41.7 \%)$ and surgeries of the liver, pancreas, biliary tract, and spleen (27.7\%) (Table 3). Table 4 shows that the proportion 
of POIs in terms of immunosuppressive agents used during surgery increased as the frequency of use increased.

The results of the univariate analysis of the POI outcomes are shown in Tables 1-4. Age, drainage, body temperature, white blood cell count, sodium level, type of surgery (thoracic surgery and lower GI tract surgery), cardiovascular agents, and immunosuppressive agents were the variables significantly associated with the occurrence of POI positivity.

\subsection{Generalized Estimating Equation Analysis in Patients Who Had Several Readmissions}

GEE analysis was performed on 1637 patients (including 198 patients who underwent several operations); therefore, the observational data of 1883 operations were used in the statistical analyses. The influencing factors predicting POIs are shown in Tables 1-4.

First, we fitted the different models with different subsets of covariates [19]. Second, we selected the model with the smallest QIC value. The risk factors were old age, history of smoking, body temperature $>38^{\circ} \mathrm{C}$, non-endoscopic surgeries, surgery in the thoracic or lower GI tract, and use of medical nutritional products during surgery. Third, the variables were analyzed using the GEE model. In the adjusted model, thoracic surgery was associated with increased odds of POIs (OR, 5.37; 95\% CI, 2.77-10.38), and the use of more than four medical nutritional products during surgery increased the odds of developing POIs (OR, 4.06; 95\% CI, 2.55-6.42) (Table 5). In addition, the sensitivity and specificity were $88.2 \%$ and $55.1 \%$ (cutoff $p>0.05$ ), respectively. Furthermore, when the GEE model was externally validated, the sensitivity and specificity were $78.7 \%$ and $48.7 \%$, respectively.

\section{Discussion}

POIs often result in prolonged hospital stays, increased reoperation and readmission rates, and increased medical costs and mortality rates. The major infection associated with POI is SSI. In this study, estimating the incidence of SSI and remote infection was considered important, and the estimated values were used in the analysis.

Niitsuma et al. reported a 30 day POI incidence in $10.7 \%$ of patients who underwent GI surgery [1]. In this study, we found that the 5 day POI incidence was $8.2 \%$, which was similar to that reported by Niitsuma et al. The risk factors for POI, including body temperature $>38^{\circ} \mathrm{C}$ and abnormal white blood cell count, were considered as indications of infection [1]. In addition, older age and history of smoking were the risk factors for SSI according to the American College of Surgeons and Surgical Infection Society, which is consistent with our results [20]. The proportion of smokers (51.1\%) was considerably higher than the Japanese average smoking rates (30\% in men and $8 \%$ in women) because history of smoking was included in our study. Non-endoscopic surgeries were considered as a risk factor in our study; a previous study reported that the incidence of POIs was lower in patients who underwent endoscopic surgery than in those who underwent open surgery $[1,20]$. Open procedures are recognized as risk factors for POIs, possibly due to microbial dysbiosis. Thoracic or lower GI tract surgery was also a risk factor in our study. We observed that esophageal surgery was most frequently performed in thoracic surgeries. Previous studies have reported that the incidence of SSIs in the esophagus is $20 \%$. In addition, colorectal surgery was the most frequently performed surgery in the lower GI tract. In colorectal surgery, open surgery increases the risk of SSI compared to that in endoscopic surgery, which is consistent with the results of our study [1].

A notable risk factor for POIs in this study was the use of medical nutritional products during surgery. To the best of our knowledge, this is the first observational study to report these risk factors, including data on the medications used during surgery. The proportions of medical nutritional products during surgery were confirmed to be associated with several categories in a variable. The proportion of the use of medical nutritional products was higher in individuals with a body mass index $<18.5 \mathrm{~kg} / \mathrm{m}^{2}$ $(29.0 \%)$ than in individuals with a body mass index of $18.5-25 \mathrm{~kg} / \mathrm{m}^{2}$. Moreover, the proportion of the use of medical nutritional products during hematopoietic stem cell mobilization and that of GI agents, which comprised more than four drugs, was higher. In unadjusted univariate analyses, increased use 
of medical nutritional products during surgery was associated with the use of other drugs during surgery, GI agents, and hematopoietic stem cell mobilizing analgesic agents. However, no significant difference was observed in the patients' demographic and clinical characteristics, clinical laboratory test results, and surgery-related variables.

Although some risk factors for infection have been reported in other patients who underwent surgery [21-23], the model constructed in this study could be applied without considering the number of hospitalizations and is applicable to several patients. When our model was applied to external data, similar sensitivity and specificity values were obtained.

Another study reported that the preventive SSI bundle was associated with a substantial reduction in the incidence of SSIs after colorectal surgery [22]. Clinical practice guidelines recommend that a bundle of measures be implemented to reduce the incidence of SSIs [21,24]. Bundled care is important in preoperative decolonization protocols for S. aureus and in the field of colorectal surgery, where bundles have been successfully applied in the intraoperative setting during closure to decrease the incidence of SSIs.

This study explored the risk factors that affect the incidence of POIs by conducting a multivariate regression analysis using electronic health records. Our study only used the electronic health records to automatically extract the data on the influential POI factors and predict POIs in the future. If it is possible to select patients with a high infection risk after surgery, infection prevention measures and care according to the degree of infection risk can be implemented at an early stage.

Our study has some limitations. "POI positivity" was defined as the presence of major pathogenic bacteria in the catheter-related bloodstream, surgical sites, urinary tract, and respiratory tract, as well as the detection of $C$. difficile and methicillin-resistant $S$. aureus in the bacterial culture test. However, patients with a compromised immune system may develop POIs caused by other bacterial strains that were not detected when the patient was evaluated for POI.

\section{Conclusions}

When patients with a high infection risk after surgery are identified immediately, infection prevention measures and care, according to the degree of infection risk, can be implemented at an early stage. Medical staff will be able to contribute to dedicated care for patients with factors identified in our study as those increasing the risk of developing POI. The widespread use of medical devices that perform such functions will also be beneficial. In future, we anticipate the development of a POI-prediction system or application based on a multivariate regression model and its incorporation into medical record systems.

Author Contributions: Data gathering, analysis, and interpretation, K.N. and T.I.; writing-original draft preparation, K.N. and T.I.; writing-review and editing, T.I., T.W., A.T., and K.A. All authors have read and agreed to the published version of the manuscript.

Funding: This research received no external funding.

Acknowledgments: We are grateful to the Division of Infection Control and Prevention Niigata University Medical and Dental Hospital for their collaboration in the early stages of this work.

Conflicts of Interest: The authors declare no conflict of interest.

\section{References}

1. Niitsuma, T.; Kusachi, S.; Takesue, Y.; Mikamo, H.; Asai, K.; Watanabe, M. Current status of postoperative infections after digestive surgery in Japan: The Japan Postoperative Infectious Complications Survey in 2015. Ann. Gastroenterol. Surg. 2019, 3, 276-284. [CrossRef] [PubMed]

2. Ohno, M.; Shimada, Y.; Satoh, M.; Kojima, Y.; Sakamoto, K.; Hori, S. Evaluation of economic burden of colonic surgical site infection at a Japanese hospital. J. Hosp. Infect. 2018, 99, 31-35. [CrossRef] [PubMed] 
3. Fujita, T.; Daiko, H. Optimal duration of prophylactic antimicrobial administration and risk of postoperative infectious events in thoracic esophagectomy with three-field lymph node dissection: Short-course versus pro-longed antimicrobial administration. Esophagus 2015, 12, 38-43. [CrossRef]

4. Nelson, L.R.; Gladman, E.; Barbateskovic, M. Antimicrobial prophylaxis for colorectal surgery. Cochrane Database Syst. Rev. 2014, 5, CD001181. [CrossRef] [PubMed]

5. Liang, H.; Jiang, B.; Manne, S.; Lissoos, T.; Bennett, D.; Dolin, P. Risk factors for postoperative infection after gastrointestinal surgery among adult patients with inflammatory bowel disease: Findings from a large observational US cohort study. JGH Open 2018, 2, 182-190. [CrossRef] [PubMed]

6. Torpy, M.J.; Burke, E.A.; Glass, M.R. Postoperative infections. JAMA 2010, 303, 2544. [CrossRef] [PubMed]

7. Nguyen, H.B.; Rivers, P.E.; Abrahamian, M.F.; Moran, J.G.; Abraham, E.; Trzeciak, S.; Huang, T.D.; Osborn, T.; Stevens, D.; Talan, A.D. Severe sepsis and septic shock: Review of the literature and emergency department management guidelines. Ann. Emerg. Med. 2006, 48, 28-54. [CrossRef] [PubMed]

8. Nedelcuta, R.M.; Baleanu, V.D.; Davitoiu, D.V.; Tenea Cojan, T.S.; Pascal, A.; Socea, B.; Ciora, C.A.; Calin, G. Group A Streptococcal infection-Biochemical and pharmacological aspects. Rev. Chim. 2019, 70, 3857-3859. [CrossRef]

9. National and State Healthcare-Associated Infections Progress Report, Centers for Disease Control and Prevention. 2017. Available online: https://www.cdc.gov/hai/data/portal/progress-report.html (accessed on 6 October 2019).

10. Weiner, M.L.; Webb, K.A.; Limbago, B.; Dudeck, A.M.; Patel, J.; Kallen, J.A.; Edwards, R.J.; Sievert, M.D. Antimicrobial-resistant pathogens associated with healthcare-associated infections: Summary of data reported to the National Healthcare Safety Network at the Centers for Disease Control and Prevention, 2011-2014. Infect. Control. Hosp. Epidemiol. 2016, 37, 1288-1301. [CrossRef] [PubMed]

11. Wisplinghoff, H.; Bischoff, T.; Tallent, M.S.; Seifert, H.; Wenzel, P.R.; Edmond, B.M. Nosocomial bloodstream infections in US hospitals: Analysis of 24,179 cases from a prospective nationwide surveillance study. Clin. Infect. Dis. 2004, 39, 309-317. [CrossRef] [PubMed]

12. National Heart, Lung, and Blood Institute. Available online: https://www.nhlbi.nih.gov/health/educational/ lose_wt/BMI/bmi-m.htm (accessed on 20 May 2020).

13. Common Terminology Criteria for Adverse Events (CTCAE). Available online: https://ctep.cancer.gov/ protocolDevelopment/electronic_applications/ctc.htm\#ctc_40 (accessed on 20 May 2019).

14. Ichihara, K.; Yamamoto, Y.; Hotta, T.; Hosogaya, S.; Miyachi, H.; Itoh, Y.; Ishibashi, M.; Kang, D. Collaborative derivation of reference intervals for major clinical laboratory tests in Japan. Ann. Clin. Biochem. 2016, 53, 347-356. [CrossRef] [PubMed]

15. Bratzler, W.D.; Dellinger, P.E.; Olsen, M.K.; Perl, M.T.; Auwaerter, G.P.; Bolon, K.M.; Fish, N.D.; Napolitano, M.L.; Sawyer, G.R.; Slain, D.; et al. Clinical practice guidelines for antimicrobial prophylaxis in surgery. Surg. Infect. 2013, 14, 73-156. [CrossRef] [PubMed]

16. National Health Insurance Price List Japan; Jihou Press: Tokyo, Japan, 2016. (In Japanese)

17. Enders, C.K. Applied Missing Data Analysis; Guilford Press: New York, NY, USA, 2010; pp. $217-253$.

18. Hilbe, M.J. Logistic Regression Models, 1st ed.; CRC Press: Boca Raton, FL, USA, 2017; pp. 441-480.

19. Aoki, S.; Miyata, H.; Konno, H.; Gotoh, M.; Motoi, F.; Kumamaru, H.; Wakabayashi, G.; Kakeji, Y.; Mori, M.; Seto, Y.; et al. Risk factors of serious postoperative complications after pancreaticoduodenectomy and risk calculators for predicting postoperative complications: A nationwide study of 17,564 patients in Japan. J. Hepatobiliary Pancreat Sci. 2017, 24, 243-251. [CrossRef] [PubMed]

20. Ban, A.K.; Minei, P.J.; Laronga, C.; Harbrecht, G.B.; Jensen, H.E.; Fry, E.D.; Itani, M.K.; Dellinger, E.P.; Ko, Y.C.; Duane, M.T. American College of Surgeons and Surgical Infection Society: Surgical Site Infection Guidelines, 2016 Update. J. Am. Coll. Surg. 2017, 224, 59-74. [CrossRef] [PubMed]

21. Zywot, A.; Lau, S.M.C.; Fletcher, H.S.; Paul, S. Bundles prevent surgical site infections after colorectal surgery: Meta-analysis and systematic review. J. Gastrointest Surg. 2017, 21, 1915-1930. [CrossRef]

22. Keenan, E.J.; Speicher, J.P.; Thacker, K.M.J.; Walter, M.; Kuchibhatla, M.; Mantyh, R.C. The preventive surgical site infection bundle in colorectal surgery: An effective approach to surgical site infection reduction and health care cost savings. JAMA Surg. 2014, 149, 1045-1052. [CrossRef] [PubMed]

23. Socea, B.; Halau, O.; Diaconu, C.; Bratu, O.G.; Neagu, P.; Dimitriu, M. Clostridium difficile infections in surgical patients (literature review). Rom. J. Med. Pract. 2019, 14, 30-33. [CrossRef] 
24. Carmichael, C.J.; Keller, S.D.; Baldini, G.; Bordeianou, L.; Weiss, E.; Lee, L.; Boutros, M.; McClane, J.; Feldman, S.L.; Steele, R.S. Clinical practice guidelines for enhanced recovery after colon and rectal surgery from the American Society of Colon and Rectal Surgeons and Society of American Gastrointestinal and Endoscopic Surgeons. Dis. Colon Rectum 2017, 60, 761-784. [CrossRef] [PubMed]

Publisher's Note: MDPI stays neutral with regard to jurisdictional claims in published maps and institutional affiliations.

(C) 2020 by the authors. Licensee MDPI, Basel, Switzerland. This article is an open access article distributed under the terms and conditions of the Creative Commons Attribution (CC BY) license (http://creativecommons.org/licenses/by/4.0/). 